\title{
Conditions for a meaningful writing retreat: Time, space, community and transition
}

\author{
Kalypso Filippou and Raakel Plamper
}

\begin{abstract}
This article investigates a five-day residential retreat for seven women from one academic institution and examines writing retreats through the analysis of texts written by the participants. The aims of this paper are 1) to develop more knowledge about the experiences of what constitutes good conditions for writing in a writing retreat context, and 2) to identify elements of a meaningful writing retreat. The experiences and reflections of the participants are examined and concludes to four conditions that shaped the meaningfulness of the retreat: transition, space, time, and community.
\end{abstract}

Keywords: academics; community; praxis; writing retreat

\begin{abstract}
Received 18 May 2021; revised version received 11 October 2021; accepted 13 October 2021. Corresponding author: Kalypso Filippou, the University of Turku, Finland (kalypso.filippou@utu.fi).
\end{abstract}

\section{Introduction}

Writing is an essential practice in academic work. The assessment of academic writing often focuses on the number of publications but for academics writing is more than publishing. Writing is also a way of communicating as well as a tool for thinking and analysing (Cloutier, 2016). When contemporary academic work is managed by results, measurable outputs and performances, many academics find their concentration shattered with multiple tasks and reporting demands (Kallio et al., 2016; Murray, 2013). Writing is a practice that needs perseverance and concentration. Fundamentally, writing is not about mechanically producing ideas on a paper, but it is about expressing oneself, about forming ones' identity and also about communicating with others - and it involves feelings.

Kiriakos and Tienari (2018) juxtapose academic writing with love and analyse it as a comprehensive experience, which involves embodied, sensuous, emotional, social, and identity-related experiences of the academics. 
Writing can be a meaningful and pleasurable practice despite academics facing a contradiction: they aim to produce as many publications as possible in a short time and a lot of time needs to be invested in thorough and meaningful writing work. To solve this contradiction, or at least to diminish its effects, academics can create practices which support the experience of meaningful ways in which to do the writing work, i.e., they can create a praxis (Räsänen, 2009). When exercising praxis, one experiences that they are doing their work well, they are doing good for others, and working feels good for themselves, for instance, when one is immersed in work (Räsänen \& Trux, 2012). Similarly, we consider a meaningful writing experience when the participants immerse themselves in what they are writing, thinking and researching (Eodice, Geller, \& Lerner, 2017). Many academics report experiences such as these during a writing retreat (Grant, 2006; Moore, 2003) since writing retreats offer distance to the fragmented daily life where multiple responsibilities are common.

In this article, we will explore a writing retreat by analyzing texts written by participants of the retreat. The main aim of this study is to develop more knowledge about the experiences of what constitutes good conditions for writing in a writing retreat context. Another aim is to identify elements of a meaningful writing retreat based on the participants' experiences. This will be achieved by analysing the participants' experiences of meaningful ways to do ones writing work (i.e., praxis) in the context of a writing retreat. The main research question of this study is:

Which conditions contribute to meaningful writing during a writing retreat?

\section{Why a writing retreat?}

The workload and competition inside the university environment has increased all around the world. Continuous pressure on writing and publishing, also known as 'publish or perish', has led to an increase of interventions such as writing courses, support groups and writing retreats aiming but also resulting in an increase of productivity and publications (Dickson-Swift et al., 2009; Grant, 2006; McGrail, Rickard, \& Jones, 2006). An increasing number of researchers from various fields have examined the participants' experiences and writing retreats' impact and results. In some of these studies the writing retreat participants had different working positions (Grant, 2006) and writing experiences (Moore, 2003) were bachelor's or master's degree students (Edwards et al., 2020; Singh, 2012) or doctoral candidates (Burford, 2018). The participants sometimes represented a variety of fields (Castle, 2017; Grant, 2006) or just one such as the field of medicine (Cable et al., 2013; Pololi, Knight, \& Dunn, 2004), geography (Edwards et al., 2020), psychology (Stanley et al., 2017) and public health (Dickson-Swift et al., 
2009). More specifically, in the field of nursing, the study of Jackson (2009), which included pairing of novice writers with mentors, indicated that writing retreats can lead to more publication submissions but also positive effects on collegial relationships and team building. Similarly, the study by Noone and Young (2019) showed that writing retreats enhanced the participants' knowledge on writing and their writing motivation.

More than the publication numbers, writing retreats have also been perceived as an opportunity to develop teamwork and bonding within departments (Dickson-Swift et al., 2009). Live-in writing retreats and the participants' experiences, their productivity and pleasures, but also understanding of themselves (or not) as writers and academics, has previously been examined by Grant (2006) and Grant and Knowles (2000). Attending writing retreats has assisted many academics in enjoying writing but also 'in learning new rituals, habits, skills or strategies for tackling the writing task' (Grant, 2006, p.488). According to Grant (2006), writing retreats can have a transgressive impact on the academic or professional development of a participant but also on the sense of selves as writers. For example, some participants from Grant's study (2006) established writing groups or organized their own retreats.

In the study by Moore (2003), at the beginning of the retreat participants identified enjoyable and negative aspects of the writing process such as an overall sense of achievement and satisfaction but also issues of confidence and maintaining momentum. However, during the retreat the participants experienced more pleasures, motivation, and productive feelings compared to their daily working lives (Moore, 2003). Moore's analysis (2003) highlighted five categories linked with effective writing: 'the establishment of a collaborative community of writers; the legitimisation of space and time for writing; physical and psychological safety of the working environment; invoked sense of engagement and "flow"; opportunities for relaxation in the context of hard work' (p. 338). Academics consider that it is essential to disengage from other academic tasks to concentrate in writing which ultimately improves their writing ability (Murray, 2013). This disengagement relates to three aspects the physical, social, and cognitive disengagement (Murray, 2013).

\section{Preparation and realisation of our writing retreat}

The facilitator of this case study writing retreat had previously participated in a women's writing away model retreat organised by Barbara Grant. Due to her positive experience, the facilitator's guide published by Grant (2008) was followed when organizing this writing retreat. The planning for the residential writing retreat 
started eight months before the retreat. The chosen location provided spaces for both individual and communal writing. Internet was also available, but the participants were advised to avoid emails or other online distractions as suggested by Grant (2008).

All academic women of a department in an academic institution were contacted via email regarding the retreat. In the email they were informed about the time and location of the retreat, the retreat's goal, the cost but also about traveling information. A draft of a programme as well as information about writing tools and spaces were provided. Moreover, a pre-retreat "assignment" was also shared where the participants had to set their own tangible and intangible goals for this retreat. For this retreat only seven people could participate (due to the center facilities) and a range of experiences as academic writers was expected. A copy of Grant's article (2006) regarding women writing away retreats was also attached in this first initial email. The email also informed the candidate participants that they will be asked to send in a title and abstract in advance of the retreat, that there will be a short meeting to discuss about the trip logistics prior the retreat, and that there will be a meeting before the retreat with all the participants to discuss the programme. A deadline for participation was given and those who wished to participate should email the facilitator and answer questions based on the "template for pre-retreat questionnaire" by Grant (2008). The number of interested participants was seven and a month prior the retreat the participants were asked to set their writing goals and send them to retreat facilitator as well as the working title of what they will be working on and a short abstract (similar to the pre-retreat questionnaire of Grant, 2008).

Following the facilitator's guide (Grant, 2008), before the retreat the facilitator planned a meeting where the participants were informed about workshop ideas, traveling information and things to bring with them. The retreat programme was adapted to provide as much writing time as possible for the participants. After negotiating the programme with the participants in the pre-retreat meeting, the retreat programme was finalized and decided that will not include collaborative editing exercise, but only one common workshop. Work-in-progress discussions would take over during dinner, thus we had individual lunch breaks but common dinners. It should be noted that traveling to the retreat location was also a common activity since we drove a van and traveled by boat.

We agreed to have breakfast all together at 08:00 every day but everyone was free to wake up whenever they preferred and stay awake as long as they wished. Each participant was autonomous in regulating their writing time. Each participant had their own laptop and was advised to consider which materials they will need beforehand in an attempt to avoid printing, thus diminishing the noise in the 
residential area. Some of the participants set an automatic reply in their email accounts stating their unavailability for those specific days.

\section{Method and data}

\section{Participants}

The seven participants were colleagues and worked at the same department but with different positions and duties. Four were doctoral candidates, one was a postdoctoral researcher, one was assistant professor and one worked as a university lecturer. Most of the participants in this research paper were doctoral candidates and all the participants represented the field of education. The authors of this paper were doctoral candidates at the time of the writing retreat and none of the other participants were their supervisors. This is mentioned here for the purpose of discussing the ethical perspective regarding power relations and dynamics. From the beginning stage of the retreat's planning there was a relaxed, open and nonhierarchical relationship between the participants. Because this was the first writing retreat for most of the participants, there was a shared feeling of excitement but also general support and understanding towards the facilitator and her decision making.

\section{Data collection and analysis}

Since this was the first retreat for the author as a facilitator and the participants' first retreat participation data was not collected during the retreat. This was chosen due to the possible influence that data collection might have had on the participants and their experiences. Therefore, two weeks after the retreat, the next questions were emailed to the participants:

1. What pleasures and successes have you identified during the retreat?

2. What problems and challenges have you identified during the retreat?

3. How has the environment of the retreat influenced your writing? Please elaborate/be as specific as possible.

4. How has the retreat influenced your academic work/writing after your return?

5. How can the retreat be developed further?

The participants were asked to respond to these questions voluntarily and anonymously. They were asked to print the questions, answer them in a written form, and then put their responses in the authors' mailing boxes. The participants were also advised when "retreat" is mentioned both the writing experience and the general retreat experience should be considered. We received written 
responses from all seven participants and the length of the texts ranged from one to two and a half pages. The responses were anonymous and numbered in ascending order.

The authors read the responses separately and a conventional content analysis was performed (Hsieh \& Shannon, 2005). This inductive category development was chosen due to the lack of pre-existing categories. Thus, each author read all the texts alone, highlighting words and quotes that captured the conditions which influenced the writing retreat. Thoughts and notes were written while code labelling followed, creating the initial coding scheme. Separately, the authors sorted the codes into categories based on the similarities and differences between the responses and conditions. To ensure reliability, the main categories were discussed, agreed and defined based on the content analysis. These categories were community, time, space, and transition. Next, the authors re-read the data and put the quotes in the main categories. The authors later checked these combinations one by one, and disagreements were resolved through discussion.

\section{Conditions of a meaningful writing retreat}

Four elements of a meaningful writing retreat were deduced from the data and identified as main themes during the content analysis: community, time, space and transition. These four conditions contributed to a meaningful writing retreat and were considered as the main aspects that have an influence on the implementation of the retreat. The conditions are explained separately even though some overlaps are noticeable. As the participants explained the retreat was characterized as a successful one due to the combination of those conditions.

The participants wrote about the successful experience of their writing work in the retreat with colorful descriptions. Writing work was described as an artistic process, which cannot be pushed too hard without harming the work (Participant 3 ). Persevering and concentrated writing and thinking work was experienced both enjoyable and fruitful (Participants 2 and 5), and it created a sense of freedom where "the text itself lead" the writer (Participant 7). Participant 5 describes the flow experience (Csikszentmihalyi, 1990) of writing:

[...] the writing itself was a pleasure too. I managed to get into a mood where writing (and doing analysis as part of writing) was something that I was able to immerse myself into. A bit similarly like in the childhood when I was playing something, just concentrated on that, without any worries about the outside world, I felt a kind of flow. There was this experience which I called "timeless time", meaning that for a 
while, time lost its meaning and I had this very peculiar experience of freedom in that sense.

We consider this quote to be a suitable example of what we consider as an overall meaningful writing experience due to 'the thrill of immersion in thought, writing, and research' Eodice, Geller, \& Lerner, 2017, p. 4). The four elements with selective quotes that highlight the thematic feature follow.

\section{Time}

The condition of time brings the temporal dimension into play as the meaning of writing time has changed. The freedom given by the time availability brought to the surface new (but also forgotten or lost) emotions. The participants frequently and strongly mentioned the concept of time in three forms: time availability, the length of the retreat and the season. According to the participants of this retreat a longer writing retreat or in a regular basis might have assisted even more their writing productivity. Responses to the question regarding challenges and problems were mainly linked with this temporal dimension. More specifically, the participants shared worries that time was running out or that more days would have been more beneficial for their writing and thinking processes.

Time availability: the participants referred to the element of time concerning its availability and the challenges they face in finding time for writing during the daily academic life. The next quotes show how the perception of "unlimited" time and freedom were not only essential for writing productivity but for embracing joy in the process of writing. This writing engagement with feelings of pleasure and meaningfulness can therefore be interpreted as praxis. More specifically, Participant 7 explained how she re-discovered the pleasure of writing because of the available time:

This time out of office and out of home, free from daily routines, reminded me of the pleasures of writing. Best thing was the time, time when we could be "selfish" and primarily just focus on our own writing. Being able to write several days in a row, and working with one text only, enabled me to move to the point when text starts flowing without 'calculative' thinking. I mean, not being forced to think like "I have two hours, now I need to get this abstract done..." It's not to say that writing was particularly easy, and super productive, but I wrote what I wanted. I moved from one part of the text to another, as I got ideas, and I let the text itself to lead me. How I could describe it: I wrote from within the text. 
When the participants were asked how the retreat has influenced their academic work and writing after their return to the university environment, all of them explained how the first days were not as productive due to their

teaching obligations, small departments tasks, planning, email responses, and limited writing time. (Participant 1)

The importance of having multiple days dedicated to writing which is a limited characteristic during their daily working life was also stressed:

I finally had the time to focus not only for a few hours but for a few days which helped in concentratioing and starting to write every morning much faster, easier and concentrated. I enjoyed being able to write whenever I wanted and as much as I wanted; after dinner, late in the evening without feeling guilt or stress that "I have 20 minutes left, hurry up!"

Participant 7 referred to the frustrations of dealing with limited time while producing texts is a constant expectation:

Writing is a slow activity in a world that gives credit on productivity, speed and fast delivery. How to deal with that frustration? And not to give in by starting to produce meaningless texts in order to be productive.

Participant 5 considered in establishing new habits inspired by the retreat related to her own time availability. More specifically, she planned on informing others that 'now I have a writing day and today I'm not available by email.' She thought of organizing smaller retreats during 'normal workweeks, for example by going to another environment (e.g. library) with a colleague and work there for the day.' (Participant 5). For some participants there were obvious stages in their flowing experience during the retreat:

The first day was good, but at least partly, it was still orientation to what I was planning to do. The second day was better, and more focused to the actual writing. The third day was the best, and I felt that I was also very productive. I just wanted to continue working, and apparently some others felt the same, as a small group of us wrote until the midnight. The fourth working day, which was the last one, was all right, 
but that was also the day when I started coming out of the bubble and realising that the retreat is coming to its end.

In this quote, time availability is featured by the description of Participant 5 who considered the fourth day of the retreat as less "successful" than the previous due to being aware that this was the last day and hence, time is limited and running out.

Length of the retreat: for Participants 4, 5 and 6 the five days available for the retreat were not sufficient:

The time we had was too short for me. It felt like I just got things going at a good speed when we already had to leave. Also, while not related only to the retreat, my writing tasks took up more time than I had anticipated, so I did not reach all my pre-set goals. However, the work needed to be done, and the retreat was a perfect place for it.

Participant 5 also mentioned that more time was necessary, however, even though

those few days were then utilized quite efficiently and there was no tiring which could have happened if the retreat would have been longer. I had this feeling that now these four days are a short time and I was conscious that these few days have to be used as efficiently and well as possible.

The same participant explained that the number of days could have been higher under certain conditions:

It depends on the amount of different kinds of duties, whether it is possible to be away for a week, for example. Family responsibilities are one issue, but also work responsibilities when you have teaching and all kinds of projects going on.

In addition, developing writing retreats in a more regular basis even in as a routine was explained by Participant 5:

the experience would "grow" and as more experienced retreaters, the participants could be able to utilize them more skillfully as a way of organising ones writing work. 
Season: the season of early autumn assisted in the general atmosphere as Participant 3 explained that

[t] he season, the weather, falling leaves of autumn and the atmosphere of the house was also very nice... I do not know if I would feel the same way with other people accompanying me, but that place had a very bright feeling to it.

Similarly, Participant 1 noted that 'from the window you could see the yard with the colorful trees. Actually the autumn colors brought some kind of beauty and calmness.' and Participant 6 suggested '[i]t would have been wonderful to have one day-off in the middle of retreat, just to relax and to make a tour of [the city]. The weather was so nice and sunny.'

This sub-dimension (season) is separated from the previous two due to its broader focus, external and uncontrolled nature. In this case the concept of time is not depended on schedules and timekeeping but proceeds to considerations related to aesthetics, natural environment, and weather.

Space

The condition of space considers the writing retreat from a spatial perspective. This spatial dimension deals with the tangible spaces of the retreat such as, the location with its facilities and surroundings but also with the intangible spaces of the retreat such as, being at a space without distractions, moving to a space that supports concentration and eliminates duties and interferences, giving space for emotions and re-discovering joy in writing. Space becomes a point of reference that supports the purpose of the retreat, to write. The specific spaces involved in the writing retreat as well as the shift to a significantly different space from the university offices had a positive impact on the writing immersion and meaningfulness.

Location, facilities, and surroundings: the participants appreciated the choice of the location since it contributed to the pleasures of the retreat. For example, Participant 1 described:

Discovering the peaceful and quite location, with calm and inspiring environment, beautiful architecture and nearby nature were also some of the pleasures of this retreat... The environment had definitely influenced my writing. The research center we stayed was perfect for a writing retreat. The location with its quite surroundings minimized the chances for any distraction... The settings of the rooms with working 
tables were useful because there was plenty of space to write while being with others or in private. There were also different types of chairs and tables/desks to sit. There were a few big tables that could "accommodate" a few participants and each room had its own desk to be in private. The plain and simple decoration assisted in keeping my eyes "focused" on my laptop. The nearby park and beautiful city centre of Tartu were great options for short walks.

The choice of house was also perceived as part of the whole positive experience:

The physical environment, the house that we were in, was a nice place. It was also essential for our experience that we had the whole house for ourselves. We were free to use all the rooms as we wished and that felt really comfortable. The house was beautiful, calm, not too shiny and actually quite cozy. It was nice to wander there in the woolen socks and enjoy the surroundings. (Participant 5)

However, the same participant indicated that

a drawback in the physical place, and that was that all sounds and noise were so easily heard in the house. I felt that everything I did disturbed others. Every step or whisper was heard by others.

Participant 6 explained how important the environment was for her:

I assume that [name of housing] was extremely suitable for retreat. Well, the walls were thin and we had to talk in a quiet voice (if we had to talk) while writing sessions but I think that we succeeded in this excellently. Actually, it was part of the pleasure to be as quite as I could and to tiptoe to the kitchen with woollen socks to have some snack or to take a cup of coffee. I was happy to get single room and I really enjoyed this possibility to do my work in my own room. My room gave a view of the park and it was so lovely to look out of the window and see all those yellow leaves when I had a short break was deep in my writing.

The facilities and surroundings of the location were also indicated as a provision for some participants: 
The peacefulness of the place; both physically and psychologically, influenced me in a very positive way. (Participant 3 )

The place and surroundings were peaceful and offered the needed infrastructure (table, chair, electricity)... Everything was easy and did not take much effort so that gave space, time and resources to writing. (Participant 2)

Space without distractions: the struggle of concentration was diminished as the retreat provided space for a few days without distractions and other duties. This contributed to more concentrated time for work and writing, but also for finding enjoyment in these tasks. The space for writing was perceived as a "luxury" by Participant 1:

I'm really longing for this luxury of not being distracted and be fully committed into writing. There was no need to worry about teaching and other obligations, just writing.

Some of the writing obstacles are the daily disturbances such as other duties, noise from the corridor, emails as explained by Participant 2. Hence, '[i]t was great that one could give permission to oneself that the email stays closed the full day (or even the full week)'. This perceived permission was also perceived as a legitimate reason for being in the retreat as Participant 5 mentioned:

I felt that during the retreat, I had a legitimate reason to be in my own bubble. I felt that I had a right not to respond to all of the emails and requests coming to me. Because I was on this (organized) retreat, I had a right to concentrate on writing. I put an automatic reply to my email and even told beforehand some of the colleagues in other universities that I am on a retreat. Because of that, I had a pleasure of being a bit "lazy" on some of my duties. (Even though I knew that they are not going to disappear and will be there waiting for me after I return).

Participant 2 was surprised to notice how much she enjoyed the concentrated writing and thinking work:

This kind of concentration one has so rarely (because of the daily conditions in work - that is strange, because that should be our job. Concentrating fully to that what is in front of one's nose produces good feeling, satisfaction and of course also results. Concentration brings up 
clarity, insight and new ideas. It is great to have the experience nowthat it is possible to create conditions to be concentrated and enjoy it. Writing, thinking, developing ideas, trying different perspectives, going there and back again, making mistakes and learning from them, renewing previous ideas - with concentration these processes are enjoyable, even if it does not always feel easy or even comfortable. Paradoxical? Maybe, but according to my writing retreat experience uncomfortable processes can be enjoyable - and I am not masochist.

\section{Community}

The condition of community includes descriptions of how the community influenced the writing retreat. The dimension of community includes the participants' perception of being members of a supportive community and sharing an inspiring atmosphere. During the retreat the condition of community supported their motivation and encouraged an immersion into their writing. The autonomy and independence that the participants had during the retreat and the contrast of feeling alone but also together was evident. Based on the participants' responses these aspects were focusing on the impact of the community on their concentration and meaningful writing.

Freedom, autonomy and independence: the retreat and the community shaped by the participants provided the participants with some sense of freedom, autonomy and independence. Participant 3 described how she

[...] never felt that pressure of being productive during the retreat. Everybody was in their own corner and ready for help and support when someone needs it. I found such environment so fruitful.

However, she also questioned if she

[...] would feel the same way with other people accompanying' her, 'everything went so well for us... I do not know if the same setting, same place and same time would work the same for everybody. I think it depends a lot on with whom you are retreating.

Similarly Participant 5 indicated that since the participants

[...] knew each other, at least on some level, there was very easy to talk to each other and share ideas and thoughts about writing in informal situations, like on a breakfast table. Also, we did not really need any 
formal rules for our working, since everything seemed to function quite naturally.

A positive peer-pressure was also shared by Participant 4:

[...] the sense of community and other people writing around me created a very positive 'sense of pressure' for me. There were many times that, if I would have been alone, I would have gotten up and taken a long break of writing, but as I saw others working around me, it was much easier for me not to get distracted.

The structure of the retreat seemed to depend according to the wishes of the group:

For us it worked well to have only few (joint activities), but if the participants would not have known each other as well, then more activities would probably have been a good thing.

Before the retreat, some participants were worried about the socializing aspect of the retreat. Participant 1 explained how being in the same house for a few days with the same people was a rare opportunity to discover her writing, socializing and concentration "limits". Similarly, Participant 3 had low expectations of the retreat, 'but seeing everyone in their little bubbles, minding their work brought some sort of peacefulness in me.' The same participant explained how she was worried about her laptop in case it would break or if she could not write due to the number of people or even feel guilty if she would not be as productive as the other participants. However, she admitted later that among all these worries, the only thing that happened was that the laptop broke but there was a spare one at the house, so her work continued smoothly.

Being separate but also together: the participants enjoyed the group atmosphere but also the freedom of choice regarding joining the others or staying alone.

We were all in the same boat, working with our own texts but still together in same space, time and spirit. Together created concentration and working spirit was not tight or oppressive at all but supportive and liberating. I think that is special, and I really appreciate everybody's participation on creating it. It is interesting that we created this atmosphere naturally, without thinking about it or planning or putting specific effort. Of course the fact that we all knew each other before was the basis for this. Maybe one could say that there was already trust 
and friendliness which then developed into this working spirit together. (Participant 2)

Peer-support was shared during the informal conversations but a general positive and supportive environment between the participants was created. As Participant 4 explained, this was not

[...] a result of any conscious efforts but happened spontaneously due to the combination of a group of colleagues who 'matched' well together and had similar hopes and plans for the retreat It was a perfect mix of communality and individuality.

Similarly, the contribution of the participants in the overall environment was highlighted by Participant 5:

I felt that the atmosphere was very warm and friendly. Everyone was getting along well and no one irritated others nor was irritated by others. At least that was how I felt. Everyone was working on themselves, but the others were therefor company when needed. The presence of others was calming.

The participants of this retreat and their personalities seemed to match as most of the participants mentioned that

[...] all participants were broad-minded and flexible and all contracts/rules we agreed were essential ones. The retreat was a good combination of being together and being alone, at least for me. (Participant 6)

The legitimacy described in the section related to time was also linked to the community aspect:

For me, being there together with others made it somehow more legitimate to be there. Also, having a break is so much nicer when there are others, too. The spirit that was created by the group was very encouraging and supportive and that was a big element in creating the ethos of our retreat. I feel thankful that I had this opportunity to be part of this group. (Participant 5) 
This balance of being separate but also together was appreciated by all the participants:

Occasionally, I forgot that the house was full of other participants when I was deep in my writing. Our shared breakfasts, lunchbreaks and dinners acted as a counterbalance to writing alone. And sauna of course. (Participant 6)

The peer-support and the collegiality among the participants contributed to the construction of a meaningful retreat:

I enjoyed the companionship, friendship, collegiality and peer-support from the other participants. I got to know my colleagues more, exchanged experiences and opinions on writing but also on life in academic, publishing, studying, creativity, challenges and on so many other topics inside and outside of the university context. Somehow it was great to see how we supported each other, exchanged practices and ideas. Especially during our common dinners and walks back to the house. A few participants read each other's work and even agreed on publishing together. The retreat, the writing process and the companion of other researchers in various positions also gave me the opportunity to consider myself as part of the academic world and reflect on my future goals and aspirations. (Participant 1)

Participant 1 considered that as all the participants were academic women in various positions, it influenced some of the topics that were discussed during the retreat. For example, there were informal discussions on support from partners, family obligations, gender positioning in academia. Participant 1 also explained how the retreat influenced her perception of her academic identity:

The bond between the participants, the experiences and discussions we had, have influenced how I see myself as part of a general community, inside our university but also outside.

\section{Transition}

The condition transition includes descriptions of how the physical transition supported participants' mental transition. Physically the participants moved from the university, office, house, and family to the retreat location. In this mental shift they moved away from those physical locations but also from the duties and routines. Mentally, this change brought writing into the focus and turned it from a 
stressful task to a meaningful one. The participants frequently mentioned how the physical transition from the university environment to the retreat's environment assisted in a mental transition. This transition came with a shift of emotions from feelings of "escaping" the busy academic and daily family life into a purposeful journey with a meaningful goal to write. The retreat was a destination that provided a supportive community, space and time for concentration and writing excitement. Legitimization was also connected to this transition:

Going away, this isolation and separation from the daily environment made the whole purpose and process more meaningful and "productive". (Participant 1)

This transition has a positive effect on their concentration during the retreat:

The fact that the location was in a neighbouring country meant that we had to travel for a few hours. Even though this time might have been used for writing it also helped us in preparing mentally for it so I don't consider it as a big problem or challenge.

I think also that the traveling time was purposeful... a kind of mental transition... We physically and spiritually moved away from our daily routines, and it takes time. We could feel the distance. Also to return, there was still time to move slowly back and reflect upon the experience on the way home. (Participant 7)

In the participants' responses the transition had a two-fold effect. On one hand there was a positive impact on their writing when going to the retreat and on the other hand the return to the university environment had an immediate negative impact mainly due to the limited time availability:

After we returned, I was so inspired and encouraged about my writing. However, sadly I needed to teach during that month, which affected my writing negatively. But I still bare the lessons we talked about in the retreat... (Participant 3)

[...] all the work tasks and the demands of family life hit me hard in the face when we returned. However, I was really motivated to finish the article I worked on in the retreat and I finished it quite quickly, which was definitely a positive thing. (Participant 4) 
After the retreat, I have been very busy and there have been many duties and deadlines that just have had to be taken care of. Actually, I have not had any peaceful writing time after the retreat. (Participant 5)

Participant 1 discovered during the retreat the importance of writing in another environment without any distractions; a practice that she might follow later. Another implication for writing practices due to this transition was noted by Participant 2:

Daily life happens. But at least I have this experience and that it is possible to do it. I just should be more aware what happens in my daily life and organize things different... I can always go back to this "state of mind" that I had in the retreat... This "going back to that experience" creates calm, concentration and one-pointedness - which of course is affected by the outer daily life disturbances-but, I claim, is still helpful. It is kind of an attitude or a working style which one can probably develop further.

\section{Discussion}

The participants expressed the positive outcomes and impact that the retreat had on them; for the advance of their academic work and writing productivity, but also for the sense of community and bonding between the participants. Similarly, to Grant's results (2006) the participants noticed a change on how they perceived themselves as writers thus also re-discovered the pleasures of writing. Attending the writing retreat 'made a difference to [the participants'] writing lives in some meaningful way-perhaps in learning new rituals, habits, skills or strategies for tackling the writing task' (Grant, 2006, p. 488). This was also evident from the participants of this study, especially when dealing with the condition of time. The participants reflected upon their own availability and considered trying new strategies to support their writing regularity. A minor difference between the findings of Grant's study (2006) was the increase of regularity in academic writing post-retreat. For some participants, the regularity of academic writing was more challenging upon the end of the retreat due to the transition to another space, the university environment and due to time restrictions because of the demanding workload and family life. As Grant (2006) explained, this might also be because the participants attended only one retreat.

The participants elaborated on how the conditions of the writing retreat affected the writing work and its meaningfulness. By praxis, we reflect upon a practical activity (such as a writing retreat) in which the participant(s) engage in a meaningful and purposeful way (Räsänen, 2009, p. 188). When a participant attends 
the practical activity and experiences it as a meaningful way to do one's work, the activity can be called a praxis. Considering the elements of writing retreat (time, space, community, transition), it is possible to define a praxis of a writing retreat. The four aspects can support the writing work and they can create an atmosphere or/and working modus for the praxis of a writing retreat to happen. In addition, the condition of community shows how praxis is embedded in social relationships.

All four conditions supported the participants immersion into their writing, thinking, and researching and hence, are regarded meaningful (Eodice, Geller, \& Lerner, 2017). By analyzing the experiences of participants of our writing retreat, we conclude that (aspects of) time, space, community and transition influence the possibility for the writing retreat praxis to happen. Feelings of unattainable meaningfulness can be noticed in the contradiction between the fragmented everyday academic work and the persevering focused writing work. During a writing retreat, it is possible to try to dispel this contradiction and direct the activity towards the focused writing work. Hence, for creating a praxis the four dimensions must be considered.

The participants' descriptions about writing define how the writing work can be done in a meaningful way, or they define what is hindering this experience to happen. The participants emphasized the necessity and importance of the time condition in the writing retreat for their immersion, motivation, and productivity. However, this dimension was also the one that was mentioned as an answer to the question regarding challenges and problems during the retreat. Despite the available time and lack of other duties and responsibilities, the participants still shared worries that time was running out or that more days would have been more beneficial for their writing and thinking processes. The struggle of cognitive disengagement (Murray, 2013) and the continuous pressures of publications follow academics across spaces and become the main obstacles for meaningful writing and creating a praxis.

Considering the dimension of community and the fact that there were only women in the retreat, it should be noted that the participants' responses did not explore in detail this aspect and how it might have influenced the retreat and its dimensions. However, the participant who shortly reflected on this aspect explained how certain discussions were facilitated by this context. A specific question on this aspect could have brought more insights and reflections on this aspect.

The dimension of transition is relatable to the concept of disengagement discussed in Murray (2013). More specifically the dimensions of time and space can be linked with the physical and social disengagements. The legitimization of the writing retreat and the mental transition can be linked with the cognitive disengagement. This legitimization was identified in the space, transition and community elements. Like Moore (2003), the participants of this retreat also 
experienced moments of pleasure, motivation and productivity, which as they compared, they were significantly more than during their daily working lives. Considering Moore's (2003) categories linked with effective writing, we find that the notion of transition as a moderator adds to the meaningfulness of the retreat.

\section{Conclusions}

The interplay of time, space, community and transition enable the writing immersion. Writing under these conditions goes beyond mere publishing but reaches emotions and previously lost pleasures of academic activities. This study contributes to extending the knowledge related to writing retreats, emotions and writing experiences during a writing retreat. The participants' quotes clearly indicate how this writing retreat boosted the community feeling of the participants and their writing output within the retreat context and afterwards. The four elements of a meaningful writing were perceived vital and could carefully be considered when organizing a writing retreat. The creation of praxis can be encouraged by considering the space, time, transition, and community when organizing a writing retreat.

This paper investigated a small-scale study with only seven participants, therefore generalisations should be done with caution. To further examine the impact that writing retreats have on academics and on their writing, more retreats need to be organized, experienced and reported. Various smaller retreats can be organized in a residential or non-residential form. Considering the current COVID19 pandemic, however, virtual writing retreats could be analysed and evaluate the dimensions identified in this article. 


\section{Author biographies}

Kalypso Filippou, $\mathrm{PhD}$, is a university lecturer at the UTUPEDA Centre for University Pedagogy and Research and the Department of Teacher Education at the University of Turku in Finland. Her research activities mainly focus on the field of higher education, international education, mobilities, and post-graduate supervision.

Raakel Plamper is a doctoral candidate at the Department of Education, University of Turku, Finland. Her research interests cover higher education, comparative education, sociology of education, academic work and history of universities. She is working on a dissertation on university students' position and role in the marketised higher education. 


\section{References}

Burford, J. (2018). The trouble with doctoral aspiration now. International Journal of Qualitative Studies in Education, 31(6), 487-503. https://doi.org/10.1080/09518398.2017.1422287

Cable, C. T., Boyer, D., Colbert, C. Y., \& Boyer, E. W. (2013). The writing retreat: A high-yield clinical faculty development opportunity in academic writing. Journal of Graduate Medical Education, 5(2), 299-302. https://doi.org/10.4300/JGME-D-12-00159.1

Castle, J. (2017). Benefits of freewriting for academic staff engaged in a writing retreat. South African Journal of Higher Education, 31(2), 124-137. https://doi.org/10.20853/31-2-1341

Cloutier, C. (2016). How I write: An inquiry into the writing practices of academics. Journal of Management Inquiry, 25(1), 69-84. https://doi:10.1177/1056492615585875

Csikszentmihalyi, M. (1990). The domain of creativity. In M. A. Runco \& R. S. Albert (Eds.), Theories of creativity (pp. 190-212). Newbury Park, CA: Sage.

Dickson-Swift, V., James, E. L., Kippen, S., Talbot, L., Verrinder, G., \& Ward, B. (2009). A non-residential alternative to off campus writers' retreats for academics. Journal of Further \& Higher Education, 33(3), 229-239. https://doi:10.1080/03098770903026156

Edwards, B., Horwood, K., Pusey, A., Hope, M., \& Haigh, D. (2020). Making space for the dissertation: A rural retreat for undergraduate students. Journal of Perspectives in Applied Academic Practice, 8(1), 147-156. https://doi:10.14297/jpaap.v8i1.355

Eodice, M., Geller, A. E., \& Lerner, N. (2017). The meaningful writing project: Learning, teaching and writing in higher education. University Press of Colorado.

Grant, B. (2006). Writing in the company of other women: Exceeding the boundaries. Studies in Higher Education, 31(4), 483-495. https://doi:10.1080/03075070600800624

Grant, B. (2008). Academic writing retreats: A facilitator's guide. Milperra: HERDSA.

Grant, B., \& Knowles, S. (2000). Flights of imagination: Academic women be(com)ing writers. International Journal \& Academic Development, 5(1), 6-19. https://doi:10.1080/136014400410060

Hsieh, H. F., \& Shannon, S. E. (2005). Three approaches to qualitative content analysis. Qualitative Health Research, 15(9), 1277-1288. 
Jackson, D. (2009). Mentored residential writing retreats: A leadership strategy to develop skills and generate outcomes in writing for publication. Nurse Education Today, 29(1), 9-15. https://doi.org/10.1016/j.nedt.2008.05.018

Kallio, K.-M., Kallio, T. J., Tienari, J., Hyvönen, T. (2016). Ethos as stake: Performance management and academic work in universities. Human Relations, 69(3), 685-709. https://doi.org/10.1177/0018726715596802

Kiriakos, C. M., \& Tienari, J. (2018). Academic writing as love. Management Learning, 49(3), 263-277. https://doi:10.1177/1350507617753560

McGrail, M. R., Rickard, C. M., \& Jones, R. (2006). Publish or perish: a systematic review of interventions to increase academic publication rates. Higher Education Research \& Development, 25(1), 19-35.

https://doi:10.1080/07294360500453053

Moore, S. (2003). Writers' retreats for academics: Exploring and increasing the motivation to write. Journal of Further \& Higher Education, 27(3), 333-342. https://doi:10.1080/0309877032000098734

Murray, R. (2013). 'It's not a hobby': reconceptualizing the place of writing in academic work. Higher Education, 66(1), 79-91. https://doi:10.1007/s10734$\underline{012-9591-7}$

Noone, J., \& Young, H. M. (2019). Creating a community of writers: participant perception of the impact of a writing retreat on scholarly productivity. Journal of Professional Nursing,35(1), 65-69. https://doi.org/10.1016/j.profnurs.2018.07.006

Pololi, L., Knight, S., \& Dunn, K. (2004). Facilitating scholary writing in academic medicine. Journal of General Internal Medicine, 19(1), 64-68. https://doi:10.1111/j.1525-1497.2004.21143.x

Räsänen, K. (2009). Understanding academic work as practical activity - and preparing (business-school) academics for praxis? International Journal for Academic Development, 14(3), 185-195. https://doi:10.1080/13601440903106502

Räsänen, K., \& Trux, M.-L. (2012). Työkirja - ammattilaisen paluu. (Workbook the return of the professional.) Helsinki: Kansanvalistusseura.

Singh, R. J. (2012). Promoting writing for research: the 'writing retreat' model. South African Journal of Higher Education, 26(1), 66-76. https://doi.org/10.20853/26-1-150

Stanley, I. H., Hom, M. A., Chu, C., \& Joiner, T. E. (2017). Increasing research productivity and professional development in psychology with a writing retreat. Scholarship of Teaching and Learning in Psychology, 3(3), 249-256. https://doi.org/10.1037/st10000089 